Article

\title{
Methodology of Classifying the Causes of Occupational Accidents Involving Construction Scaffolding Using Pareto-Lorenz Analysis
}

\author{
Anna Hoła ${ }^{1}$, Marek Sawicki ${ }^{2}$ and Mariusz Szóstak ${ }^{2, *}$ \\ 1 Department of Building Physics and Computer Aided Design, Faculty of Civil Engineering, \\ Wroclaw University of Science and Technology, 50-370 Wrocław, Poland; anna.hola@pwr.edu.pl \\ 2 Department of Construction Technology and Management, Faculty of Civil Engineering, \\ Wroclaw University of Science and Technology, 50-370 Wrocław, Poland; marek.sawicki@pwr.edu.pl \\ * Correspondence: mariusz.szostak@pwr.edu.pl; Tel.: +48-71-320-23-69
}

Received: 26 October 2017; Accepted: 25 December 2017; Published: 1 January 2018

\begin{abstract}
This article presents the developed methodology of classifying and evaluating the causes of accidents involving construction scaffolding. This methodology allows the causes of accidents to be identified, classified into generic groups, and also allows the importance of individual causes in their generic groups to be assessed. For the classification of causes, the Technical-Organizational-Human $(\mathrm{TOH})$ method was used. Its assumption is the division of causes into technical (T), organizational $(\mathrm{O})$, and human $(\mathrm{H})$ ones. Pareto-Lorenz analysis and $\mathrm{ABC}$ classification were used to identify the most important causes. The developed methodology was used to analyze and assess the causes of accidents that involve construction scaffolding using the data of accidents that occurred in Poland as an example. The use of the proposed methodology in different countries will enable the results of the conducted studies and analysis to be compared, and conclusions that would be of a great importance in accident prevention to be drawn.
\end{abstract}

Keywords: civil engineering; occupational accidents; construction scaffolding; causes of accidents; Pareto-Lorenz analysis

\section{Introduction}

The construction industry is characterized by a high level of hazard to the health and life of employees. This is confirmed by numerous publications and reports from organizations and institutions that deal with occupational safety issues [1,2].

According to Hoła and Szóstak [3], the accident rate in the 28 countries of the EU in 2014 indicate that the construction industry was in third place among all sections of the economy regarding the overall number of occupational accidents; in second place regarding the frequency rate of accidents that cause more than three days of absence from work; and in second place regarding the frequency rate of fatal occupational accidents. Undoubtedly, the accident phenomenon in the construction industry is the result of a number of causes related to hazardous working conditions, the high variability of working conditions, and dangerous employee behavior [4,5]. Haslam et al. [6] stated that the key factors in accidents are: problems arising from workers or the work team, workplace issues, shortcomings with equipment, problems with suitability and condition of materials, and deficiencies with risk management.

A particular threat to the life and health of employees occurs when working at heights $[7,8]$. Work at heights includes activities performed on scaffolding and ladders, poles and masts, tower constructions and chimneys, as well as high building constructions that do not have ceilings or 
adequately protected edges of ceilings. The research has shown that falls from scaffolding are the biggest potential threat on a construction site and each year cause a significant number of fatalities [9].

Accidents at work involving scaffolding are a result of various causes. The analysis and comparison of the causes of these accidents and their validity is not in line with the freedom of their classification in different countries, and also not conducive with the lack of both a unified methodology of identifying causes and the assessment of their validity. The gaps that exist in this area mean that the analysis of results of research on accidents is often limited to statistical analyses. This article is intended to fill this gap by proposing both a unified methodology for the classification of causes of occupational accidents involving scaffolding, as well as the methodology for assessing their validity. In addition, another objective is to present an example of the application of the developed methodology using data on occupational accidents involving scaffolding that occurred in Poland.

The article was organized in the following way: Section 2 presents a review of the literature related to the topic of the article and also the reason for undertaking the research topic. Section 3 discusses the proposed methodology of classifying and assessing the validity of causes of accidents involving construction scaffolding. Section 4 contains an example that illustrates the application of the proposed methodology for data on accidents that occurred in Poland. Finally, Section 5 is a summary that identifies the most important causes of accidents involving construction scaffolding.

\section{Literature Review}

Causes of work-related accidents on scaffolding were investigated by the authors of articles [10-12]. Liy et al. [10] indicate that the main cause of falls from roofs and scaffolding is a lack of protective barriers. Whitaker et al. [11] found that the most common causes of these accidents were the following: the use of faulty elements, arbitrary modification of the scaffolding structure, a lack of barriers, and also easily detectable structural errors. In turn, the results of studies conducted in the UK by Suraji et al. [12] revealed that the most common causes of accidents were: violations of existing regulations, ignorance of the principles of safe work practices, insufficient equipment of employees and workplaces in measures of individual and collective protection and also an improperly conducted construction process. The above results are also confirmed by Chi and Han [13].

Halperin and McCann [14] showed a strong statistical correlation between the defects in a scaffolding structure and the risk of falling, and also between applied practices in the area of work safety on scaffolding and the competence of people conducting trainings. Studies carried out by Evanoff et al. [15] have also shown that work safety on scaffolding can be improved with the use of appropriate training methods.

Wong et al. [16] analyzed falls from height in Hong Kong. They classified the factors affecting the accidents into four classes, namely ill planning, violation, hidden hazards created by others and incapable staffing. In addition, the authors identified irregularities in the management of a building site, which included: a lack of risk control, the use of unsafe methods and procedures and also improper training and supervision of work.

The research presented in the above-mentioned articles is of a statistical survey nature. On the basis of the analysis of a specific set of accidents, the percentage share of different causes that lead to the occurrence of accidents were identified.

A methodological approach to the analysis of the causes of accidents in the construction industry is presented by the authors of publications [17-20]. Gibb et al. [17,18] classify the root causes of an occupational accident on a construction site as: failing to identify an unsafe condition that existed before or after an activity started; deciding to proceed with a work activity after a worker identifies an existing unsafe condition; deciding to act in an unsafe manner regardless of initial conditions. Błazik-Borowa et al. $[19,20]$ indicate that conditions occurring throughout the 'life cycle' of scaffolding-including the phase of preparing documentation related to scaffolding, the selection of assembly elements, assembly and operation, and also dismantling of scaffolding — have a great impact 
on the occupational safety of scaffolding. Damage to some elements and also errors committed during individual phases can affect the occupational safety of a structure during its operation.

According to the literature survey, the problem of occupational accidents involving construction scaffolding occurs in many countries. As already mentioned in the introduction, this problem is noticed, but is analyzed in various ways with the causes of accidents and their validity being classified freely. It can be concluded that there is a lack of unified methodology for identifying causes and assessing their validity. This methodology would allow the results obtained in different countries or regions to be compared, and appropriate conclusions on them to be formulated on their basis. Based on the conducted research and analyses, the authors proposed to fill in the gaps existing in this area, mainly through:

- Developing a methodology for the classification of causes of accidents at work involving construction scaffolding, which is based on the division of causes into three generic groups: technical $(T)$, organizational $(O)$, and human $(H)$.

- Developing a methodology for assessing the importance of particular causes in particular generic groups, called the $\mathrm{ABC}$ classification, according to which the causes of accidents are divided into three validity classes: important causes (A), relevant causes (B), irrelevant causes (C).

This can be the basis for conducting similar research in other areas of construction activity, which could be important for comparison purposes. The results of comparative research can be the basis for determining the most dangerous areas of the construction industry. Knowledge of the causes of accidents will allow labor law regulations to be properly formulated or modified, and preventive activities and training in the field of occupational safety to be properly targeted. This can reduce the number of accidents involving scaffolding.

\section{Proposed Research Methodology}

Every occupational accident is caused by at least several causes. For the purpose of the conducted research, the definition of a cause of an accident was assumed as all deficiencies and irregularities related to: employees and their abnormal behavior, material factors, general organization of work, and the organization of a workplace.

For the purpose of the developed methodology, the classification proposed by the European Statistical Office of the European Union EUROSTAT was assumed, which distinguishes eight subgroups of causes of occupational accidents, namely: $P_{1}$-the inappropriate state of the material factor; $P_{2}$ - the inappropriate general organization of work; $P_{3}$-the inappropriate organization of a workplace; $P_{4}$ - the lack of appropriate material factors or inappropriate use of these factors; $P_{5}$ - the lack of using protective equipment by an employee; $P_{6}$-inappropriate unlawful employee behavior; $P_{7}$ - the psychophysical condition of an employee that does not enable safe work to be carried out; $P_{8}$-inappropriate employee behavior.

The set of causes of occupational accidents can be written as

$$
P=\left\{P_{g}: g=1, \ldots, 8\right\}
$$

where $P$-the set of causes identified in the analysed accidents, $P_{g}$ - a subgroup of causes $(g=1, \ldots, 8)$.

Moreover, the so-called TOH method [21] was adopted and is one of the most commonly used classifications of causes of accidents in the assessment of occupational accidents. It assumes that each accident is the result of three types of causes: technical $(T)$, organizational $(O)$, and human $(H)$. Therefore, the set $P$ of all causes of occupational accidents is the sum of the subset $T$ representing the technical causes, subset $O$ involving the organizational causes and subset $H$ constituting the human causes.

$$
P=T \cup O \cup H
$$


Technical, organizational, and human causes involve the causes of the following subgroups

$$
T=\left\{P_{g}: g=1\right\} \quad O=\left\{P_{g}: g=2,3\right\} \quad H=\left\{P_{g}: g=4, \ldots, 8\right\}
$$

In addition, in each of these $T, O, H$ sets, several or more specific causes are listed

$$
T=\left\{t_{k}: k=1, \ldots, K\right\} \quad O=\left\{o_{m}: m=1, \ldots, M\right\} \quad H=\left\{h_{n}: n=1, \ldots, N\right\}
$$

where $t_{k}$-a detailed cause in set $T,(k=1, \ldots, K), o_{m}$-a detailed cause in set $O,(m=1, \ldots, M)$, $h_{n}$-a detailed cause in set $H,(n=1, \ldots, N)$.

Each cause identified during the assessment of an accident is eligible for an appropriate subset of detailed causes: $t_{k}(k=1, \ldots, K)$ or $o_{m}(m=1, \ldots, M)$ or $h_{n}(n=1, \ldots, N)$. The scheme of the classification of causes of accidents according to the TOH method is shown in Figure 1.

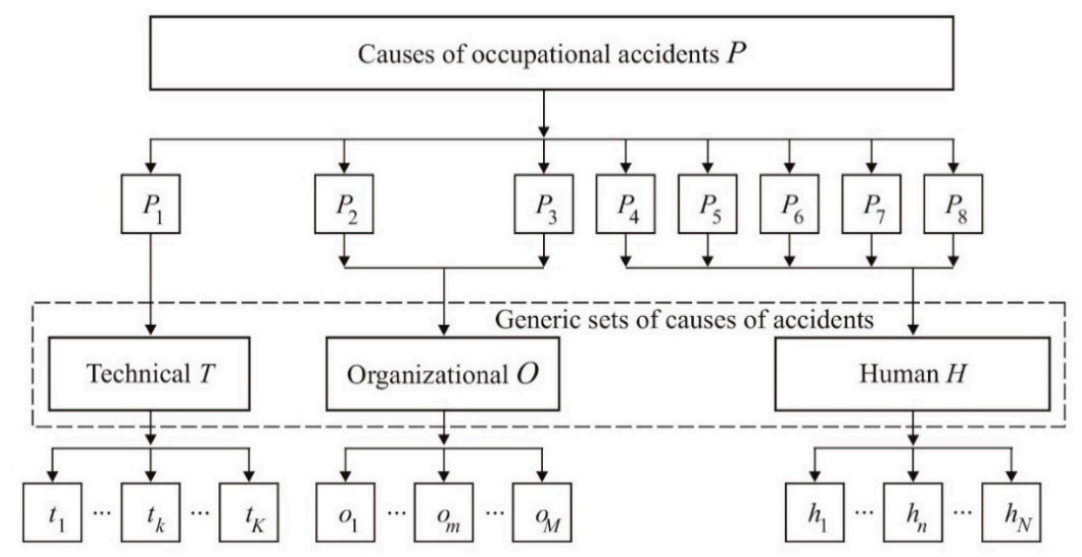

Figure 1. Scheme of the classification of causes of accidents according to the TOH method.

It is proposed to adopt the $\mathrm{TOH}$ methodology as a benchmark for classifying the direct causes of accidents at workplaces that use building scaffolding. The causes of accidents, which were identified in the post-accident protocols, were classified to the three defined in the $\mathrm{TOH}$ method subset of causes (technical, $T$; organizational, $O$; and human, $H$ ).

Pareto-Lorenz analysis and $\mathrm{ABC}$ classification are proposed to identify the causes with the greatest importance [22,23]. The proposed calculation methodology is universal, which means that it applies to the analysis of each of the three groups of causes of accidents involving scaffolding $(T, O, H)$. The procedure of the carried out analysis is as follows:

- Defining specific detailed causes and their cardinalities in the analyzed generic group. This information can be presented as a sequence of ordered pairs of numbers $\left(p_{x}, a_{x}\right)$, where $p_{x}(x$ $=1, \ldots, X)$ (represents the identified detailed cause and $a_{x}$ indicates the number of occurrences of the examined cause in the analysed subset $T, O$, or $H$.

- Organizing sequences of pairs of numbers $\left(p_{x}, a_{x}\right)$ that describe the analysed causes in a descending order. The position of a pair in the ordered sequence is determined by the number $a_{x}$ of the occurrences of attribute px in the subset $T, \mathrm{O}$ or $\mathrm{H}$ according to the rule

$$
\text { if } a_{x+1} \geq a_{x} \text {, then } p_{x+1}<p_{x}
$$

- Determining the percentage share $u_{x}$ of occurrences of cause px in the total of all examined causes according to the following formula

$$
u_{x}=\frac{a_{x}}{\sum_{1}^{x=X} a_{x}} \cdot 100 \%
$$


- Determining the percentage of the cumulated sum of subsequent causes according to the following formula

$$
S_{x}=\sum_{1}^{x} u_{x} \quad x=1, \ldots, X .
$$

- Defining the affiliation of specific causes to one of the valid classes in order to classify causes according to the degree of their influence on the occurrence of an accident, $\mathrm{ABC}$ analysis, which is known in economics and is simple-to-use, was applied [23]. According to the ABC method, it is necessary to divide causes from the set into three subgroups. It was assumed that:

$\sqrt{ } \quad$ the set of important causes, designated as A, forms causes that account for $80 \%$ of all the causes that are attributable to a particular cause group,

$\sqrt{ } \quad$ the set of less relevant causes, designated as B, forms causes that account for $15 \%$ of all the causes that are attributable to a particular cause group,

$\sqrt{ } \quad$ the set of irrelevant causes, designated as C, forms causes that account for $5 \%$ of all the causes identified in the set.

The proposed methodology of classifying and evaluating the validity of causes of accidents involving scaffolding is presented in Figure 2.

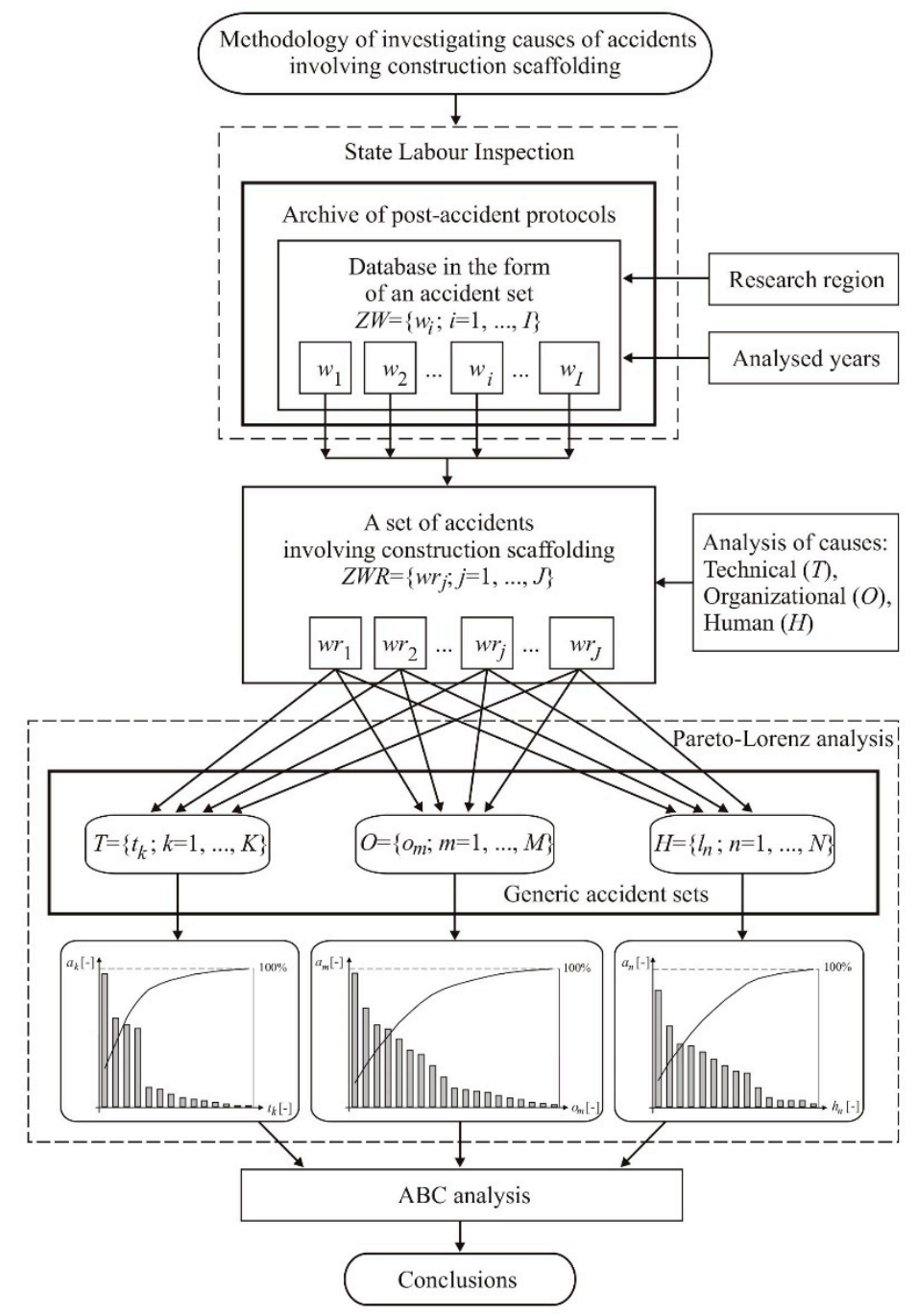

Figure 2. Methodology of classifying and evaluating the validity of causes of accidents involving scaffolding. 


\section{Application of the Proposed Methodology}

\subsection{Information About the Used Database}

The proposed research methodology was used to identify and assess the causes of accidents involving construction scaffolding that occurred in Poland. The authors had access to post-accident protocols provided by the National Labor Inspectorate, and these protocols formed the database. Occupational accidents in the construction industry, which took place in the following voivodeships-Dolnoslaskie, Lodzkie, Malopolskie, Mazowieckie, and Wielkopolskie-were analyzed. The analysis covered the last eight years, i.e., the years between 2008 and 2015 (data for 2016 is not yet available). The direct source of information on the course of accidents was a set of about 700 postaccident protocols created by labor inspectors after the occurrence of an accident.

$$
\mathrm{ZW}=\left\{w_{i}: i=1, \ldots, \mathrm{I}\right\}
$$

where $Z W$ - an analysed set of accidents, $w_{i}$ - an accident event (single accident) $i$, which occurred in the years 2008-2015, I = 700.

A detailed analysis of the protocols revealed that during the assessed period of time there were 177 accidents at workplaces in which construction scaffolding was used

$$
Z W R=\left\{w r_{j}: j=1, \ldots, J\right\}
$$

where $Z W R$ - a set of accidents involving construction scaffolding, $w r_{j}$ - an accident event (single accident) $j$ involving construction scaffolding, $\mathrm{J}=177$.

Based on analysis of this set, 1132 causes of accidents were identified. Technical causes accounted for $24.6 \%$, organizational for $48 \%$, and human for $27.4 \%$ of all the identified causes.

\subsection{Research Results}

Table 1 includes complete information regarding the identified technical, organizational and human causes, the cardinality of the occurrence of individual causes in the group of analyzed accidents, the percentage share of individual causes and the cumulative share of the subsequent causes, and also the classification of causes into the specific validity class.

\begin{tabular}{|c|c|c|c|c|c|}
\hline & Type of Cause & $\begin{array}{l}\text { Cardinality of } \\
\text { Occurrence } a_{x}\end{array}$ & $\begin{array}{l}\text { Share } \\
u_{x}(\%)\end{array}$ & $\begin{array}{l}\text { Cumulative } \\
\text { Share } S_{x}(\%)\end{array}$ & $\begin{array}{c}\text { Validity Class } \\
\text { of Cause }\end{array}$ \\
\hline \multicolumn{6}{|c|}{ Technical causes $(T) ; T=\left\{t_{k}: k=1, \ldots, K\right\}$} \\
\hline$t_{2}$ & Lack of or inadequate measures of collective protection & 52 & $18.8 \%$ & $46.7 \%$ & A \\
\hline$t_{3}$ & Improper spatial structure of scaffolding & 48 & $17.4 \%$ & $64.1 \%$ & A \\
\hline$t_{5}$ & Design defects of scaffolding that are a source of a hazard & 12 & $4.3 \%$ & $85.1 \%$ & B \\
\hline$t_{6}$ & Use of substitute materials & 11 & $4.0 \%$ & $89.1 \%$ & B \\
\hline$t_{7}$ & Lack of or incorrect signaling of hazards & 8 & $2.9 \%$ & $92.0 \%$ & B \\
\hline$t_{8}$ & Inadequate strength of scaffolding & 6 & $2.2 \%$ & $94.2 \%$ & $\mathrm{~B}$ \\
\hline$t_{12}$ & Excessive use of scaffolding & 2 & $0.7 \%$ & $99.2 \%$ & $\mathrm{C}$ \\
\hline$t_{13}$ & Improper repairs and renovations of scaffolding & 1 & $0.4 \%$ & $99.6 \%$ & C \\
\hline$t_{14}$ & Failure to meet required technical parameters & 1 & $0.4 \%$ & $100 \%$ & $\mathrm{C}$ \\
\hline
\end{tabular}

Table 1. Subsets of technical $(T)$, organizational $(O)$, and human $(H)$ causes. 
Table 1. Cont.

\begin{tabular}{|c|c|c|c|c|c|}
\hline \multicolumn{6}{|c|}{ Organizational causes $(O) ; O=\left\{o_{m}: m=1, \ldots, M\right\}$} \\
\hline$o_{1}$ & Lack of supervision & 96 & $17.7 \%$ & $17.7 \%$ & A \\
\hline$o_{2}$ & $\begin{array}{l}\text { Admission of scaffolding to operation without the } \\
\text { required inspection and supervisions }\end{array}$ & 71 & $13.1 \%$ & $30.8 \%$ & A \\
\hline$o_{3}$ & $\begin{array}{l}\text { Acceptance of deviations from the rules and regulations of } \\
\text { occupational health and safety }\end{array}$ & 59 & $10.9 \%$ & $41.7 \%$ & A \\
\hline$o_{4}$ & $\begin{array}{l}\text { Lack of or inadequate training in the area of occupational } \\
\text { health and safety }\end{array}$ & 56 & $10.3 \%$ & $52.0 \%$ & A \\
\hline$o_{5}$ & $\begin{array}{l}\text { Admission of an employee to work without medical } \\
\text { examination or with medical contraindications }\end{array}$ & 49 & $9.0 \%$ & $61.0 \%$ & A \\
\hline$o_{6}$ & $\begin{array}{l}\text { Lack of instructions of safe execution of work } \\
\text { on scaffolding }\end{array}$ & 41 & $7.6 \%$ & $68.6 \%$ & A \\
\hline$o_{7}$ & Inadequate passages and paths & 38 & $7.0 \%$ & $75.6 \%$ & A \\
\hline$o_{8}$ & Inadequate professional training of an employee & 30 & $5.5 \%$ & $81.1 \%$ & A \\
\hline$o_{9}$ & Lack of personal protective equipment & 22 & $4.0 \%$ & $85.1 \%$ & A \\
\hline$o_{10}$ & $\begin{array}{l}\text { Acceptance of the use of improper technology } \\
\text { by supervisors }\end{array}$ & 14 & $2.6 \%$ & $87.7 \%$ & B \\
\hline$o_{11}$ & Improper placement and storage of work items & 13 & $2.4 \%$ & $90.1 \%$ & $\mathrm{~B}$ \\
\hline$o_{12}$ & Incorrect coordination of collective work & 12 & $2.2 \%$ & $92.3 \%$ & B \\
\hline$o_{13}$ & Incorrect job sharing or task scheduling & 11 & $2.0 \%$ & $94.3 \%$ & B \\
\hline$o_{14}$ & Incorrect location of equipment at a workstation & 9 & $1.6 \%$ & $95.9 \%$ & B \\
\hline$o_{15}$ & Improper selection of personal protective equipment & 7 & $1.3 \%$ & $97.2 \%$ & C \\
\hline$o_{16}$ & $\begin{array}{l}\text { Removal of unnecessary items, substances, or energy, } \\
\text { e.g., waste }\end{array}$ & 6 & $1.1 \%$ & $98.3 \%$ & $\mathrm{C}$ \\
\hline$o_{17}$ & Incorrect commands of superiors & 4 & $1 \%$ & $99.0 \%$ & $\mathrm{C}$ \\
\hline$o_{18}$ & Performing work when short-staffed & 3 & $0.6 \%$ & $99.6 \%$ & $\mathrm{C}$ \\
\hline$o_{19}$ & $\begin{array}{l}\text { Performing work on command that is not included in the } \\
\text { scope of an employee's duties }\end{array}$ & 2 & $0.4 \%$ & $100.0 \%$ & $\mathrm{C}$ \\
\hline \multicolumn{6}{|c|}{ Human causes $(H) ; H=\left\{h_{n}: n=1, \ldots, N\right\}$} \\
\hline$h_{1}$ & $\begin{array}{l}\text { Failure to use personal protective equipment by } \\
\text { an employee }\end{array}$ & 60 & $19.3 \%$ & $19.3 \%$ & A \\
\hline$h_{2}$ & Disregard of a danger & 42 & $13.5 \%$ & $32.8 \%$ & A \\
\hline$h_{3}$ & $\begin{array}{l}\text { Lack of or improper use of a material factor by } \\
\text { an employee }\end{array}$ & 33 & $10.6 \%$ & $43.4 \%$ & A \\
\hline$h_{4}$ & Consumption of alcohol, drugs or psychotropic substances & 32 & $10,3 \%$ & $53.7 \%$ & A \\
\hline$h_{5}$ & Being surprised by an unexpected event & 29 & $9.3 \%$ & $63.0 \%$ & A \\
\hline$h_{6}$ & $\begin{array}{l}\text { Going to, driving through, or staying in places that } \\
\text { are forbidden }\end{array}$ & 25 & $8.0 \%$ & $71.0 \%$ & A \\
\hline$h_{7}$ & Insufficient concentration & 22 & $7.1 \%$ & $78.1 \%$ & A \\
\hline$h_{8}$ & $\begin{array}{l}\text { Ignorance of hazards, regulations, and rules of } \\
\text { occupational health and safety }\end{array}$ & 19 & $6.1 \%$ & $84.2 \%$ & A \\
\hline$h_{9}$ & $\begin{array}{l}\text { Performing work that is not included in the scope of an } \\
\text { employee's duties }\end{array}$ & 18 & $5.8 \%$ & $90.0 \%$ & B \\
\hline$h_{10}$ & $\begin{array}{l}\text { Entering an endangered area without making sure that } \\
\text { there is no danger }\end{array}$ & 11 & $3.5 \%$ & $93.5 \%$ & B \\
\hline$h_{11}$ & Failure to use collective protection measures & 6 & $1.9 \%$ & $95 . \%$ & $\mathrm{~B}$ \\
\hline$h_{12}$ & Sudden illness, physical deterioration, fatigue & 4 & $1.3 \%$ & $97 \%$ & $\mathrm{C}$ \\
\hline$h_{13}$ & Disregard of superiors' commands & 4 & $1.3 \%$ & $98 \%$ & $\mathrm{C}$ \\
\hline$h_{14}$ & Improper pace of work & 4 & $1.3 \%$ & $99 \%$ & $\mathrm{C}$ \\
\hline$h_{15}$ & Lack of experience & 2 & $0.6 \%$ & $100 \%$ & $\mathrm{C}$ \\
\hline
\end{tabular}

\subsection{Analysis of the Obtained Results}

Figure 3 presents a bar graph that illustrates the cardinality of occurrences of the individual identified technical causes ordered from the maximum to the minimum (the so-called Pareto graph), 
and also the cumulative percentage share of subsequent causes (in the form of the so-called Lorenz curve). The graph also highlights the areas-A, B, C-that include causes specified as significant, minor, and irrelevant.

\section{TECHNICAL CAUSES}

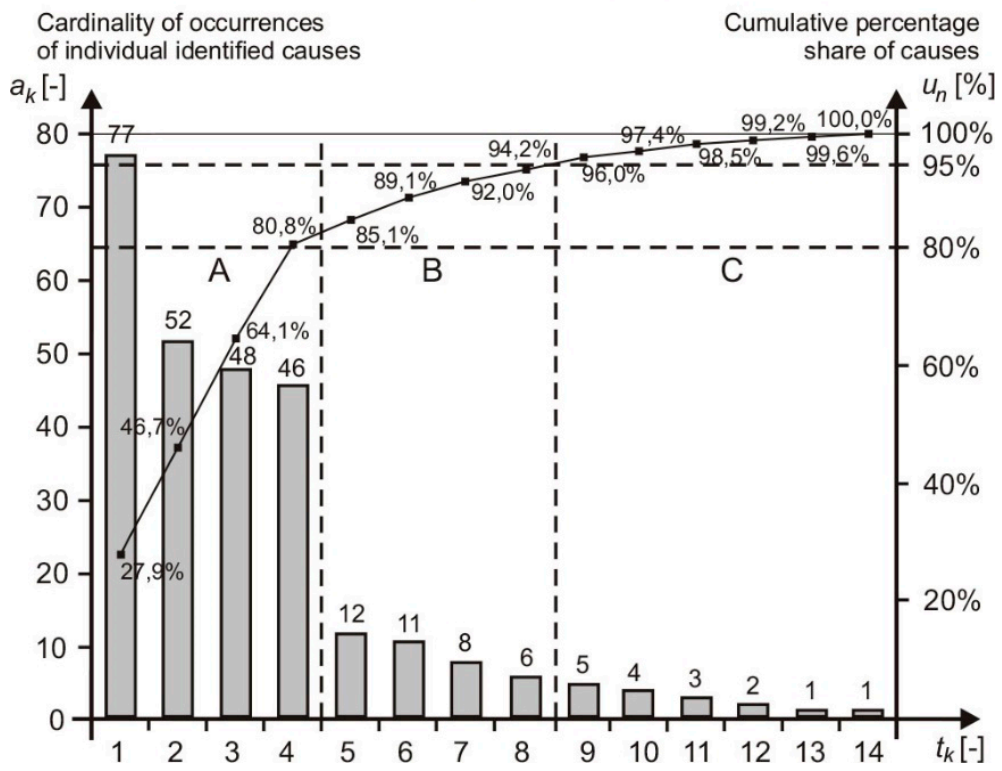

Figure 3. Pareto-Lorenz chart of identified technical causes.

A total 278 technical causes were identified in the analyzed group of accidents. The causes identified with the letter $\mathrm{A}$ are of the greatest importance for the assurance of occupational safety. They represent $80.8 \%$ of all identified technical causes. These are the causes designated in Table 1 as $t_{1}, t_{2}, t_{3}, t_{4}$.

In turn, Figure 4 shows a bar graph illustrating the cardinality of occurrences of the identified organizational causes ordered from the maximum to the minimum (the so-called Pareto graph), and also the cumulative percentage share of subsequent causes (in the form of the so-called Lorenz curve). The graph also highlights the areas-A, B, C-that include causes specified as significant, minor, and irrelevant.

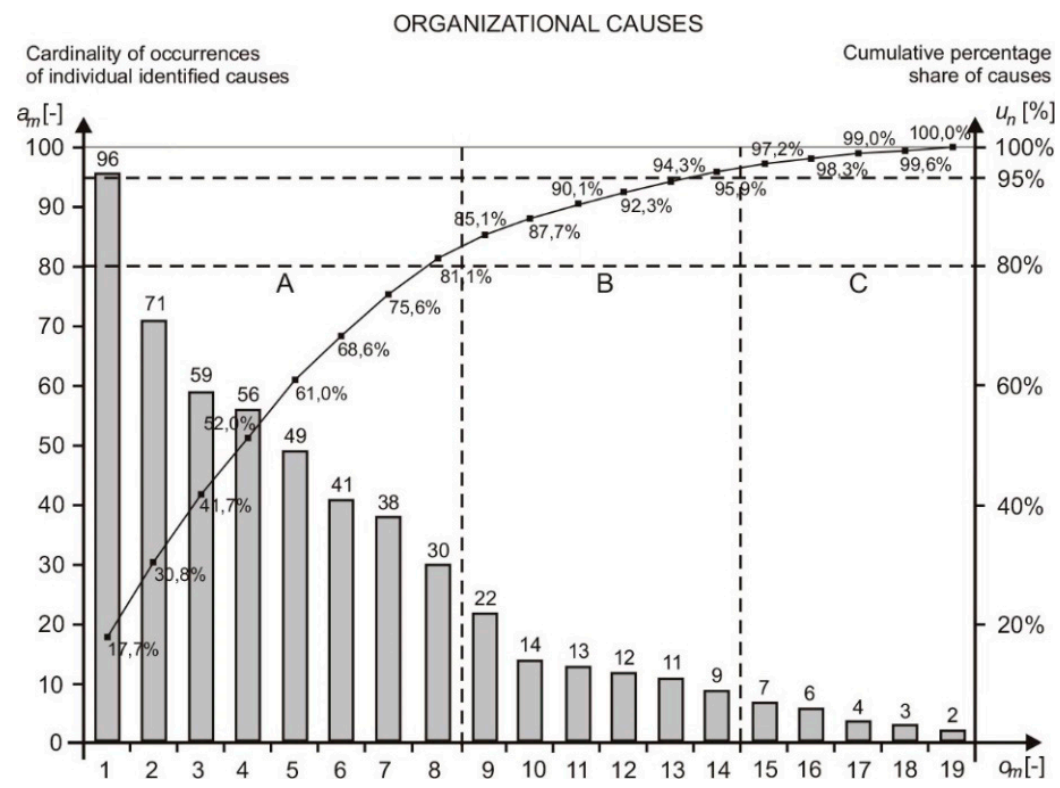

Figure 4. Pareto-Lorenz chart of identified organizational causes. 
A total 543 organizational causes were identified in the analyzed group of accidents. The causes identified with the letter A are of the greatest importance for the assurance of occupational safety. They represent $81.1 \%$ of all identified organizational causes. These are the causes designated in Table 1 as $o_{1}, o_{2}, \ldots, o_{7}, o_{8}$.

Moreover, Figure 5 shows a bar graph illustrating the cardinality of occurrences of the identified human causes ordered from the maximum to the minimum, and also the cumulative percentage share of subsequent causes. The graph also highlights the areas-A, B, C-that include causes specified as significant, minor, and irrelevant.

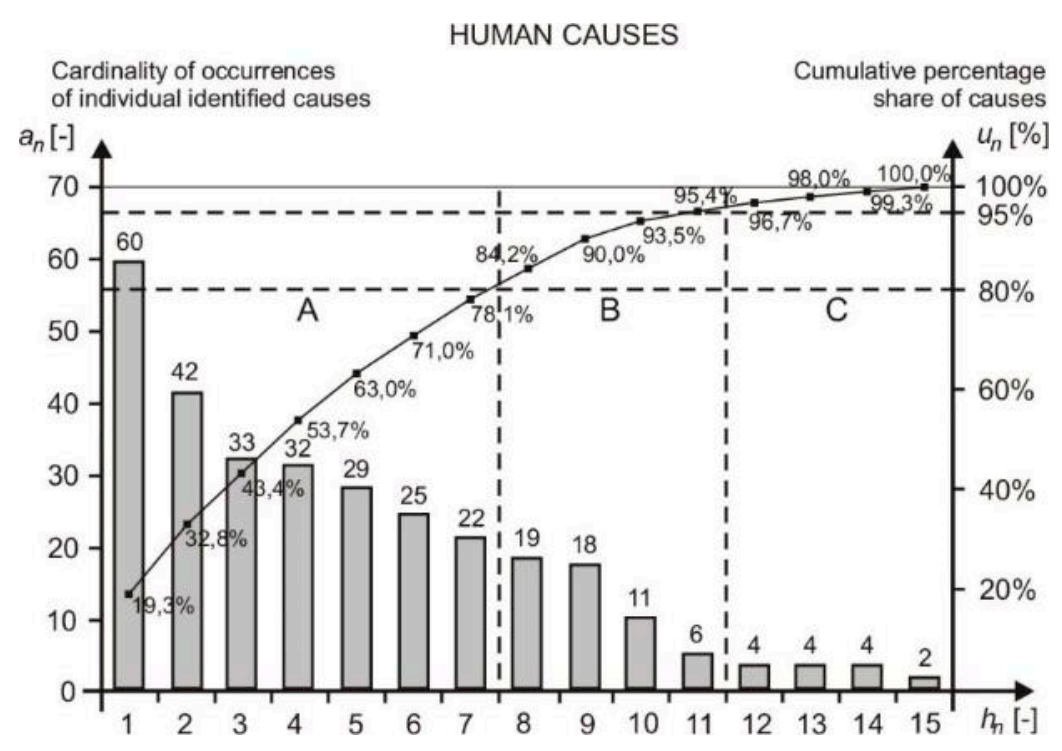

Figure 5. Pareto-Lorenz chart of identified human causes.

A total 311 human causes were identified in the analyzed group of accidents. The causes identified with letter A are of the greatest importance for the assurance of occupational safety. They represent $84.2 \%$ of all identified human causes. These are the causes designated in Table 1 as $h_{1}, h_{2} ., \ldots, h_{6}, h_{7}$.

\section{Summary}

The article proposes a methodology of classifying the causes of occupational accidents involving construction scaffolding into generic groups that include technical, organizational, and human causes, as well as an assessment of the importance of causes in particular groups. The proposed methodology uses the Pareto-Lorenzo analysis, known in economics as the so-called ABC analysis. The application of the developed methodology was also presented using data on occupational accidents in Poland as an example.

The application of the developed methodology in the analysis of occupational accidents involving construction scaffolding that took place in Poland, allowed the following causes of the greatest importance for occupational safety to be identified:

- In the group of technical causes: a lack of or improper devices protecting workplaces on scaffolding, improper collective protection measures, improper stability of scaffolding or its components, and also improper spatial structure of scaffolding.

- In the group of organizational causes, first and foremost: a lack of direct supervision by a construction manager or executive manager during the performance of work, approval of scaffolding for operation without the required inspections and supervisions, tolerance by the supervisors of derogations from the rules and regulations of occupational health and safety, a lack of or inadequate training of employees in occupational health and safety, giving permission to an employee to work with medical contraindications or without medical examination, and also a 
lack of instructions for safe work on scaffolding or failure to familiarize with such instructions by employees.

- In the group of human causes, first of all: failure to use personal protective equipment by an employee; disregard of a danger; inappropriate psychophysical state of an employee due to the consumption of alcohol, drugs or psychotropic substances; being surprised with an unexpected event; going to, driving through, or being in unauthorized places; arrogant and risky behavior of an employee causing disregard of a hazard, and also improper behavior of an employee due to ignorance of rules and regulations of occupational health and safety.

The proposed methodology can be applied in both the area of scientific research and also in practice regarding the issues related to occupational safety management in the construction industry. It has a universal character, which means that it can be used in the research and analysis of causes of accidents that are related to not only scaffolding, but also to those that occur in different conditions and circumstances of construction works. The research and analysis results obtained with the aid of this methodology can be the basis for comparing accident rates in various construction areas, and also the basis for defining the most dangerous areas. Moreover, the proposed methodology can be used as a tool to compare accidents in different countries, regions, or enterprises.

The practical aspect of the proposed methodology is connected to the possibility of drawing conclusions, which are important in accident prevention, on the basis of the obtained results. In particular, the determination of the validity of individual causes of accidents will allow the causes with the greatest importance for work safety to be indicated and preventive actions to be properly targeted. The results obtained using the developed methodology may also form the basis for formulating new legal regulations and modifying existing ones in the area of occupational safety. The above-mentioned activities will certainly contribute to the reduction of the accident rate and the achievement of the intended objective, which is zero accidents in the construction industry.

Acknowledgments: The article is the result of the implementation by the authors of the research project No. 244388 "Model of the assessment of risk of the occurrence of building catastrophes, accidents, and dangerous events at workplaces with the use of scaffolding", financed by NCBiR within the framework of the Program for Applied Research on the basis of contract No. PBS3/A2/19/2015.

Author Contributions: Mariusz Szóstak conceived and designed the proposed methodology. Marek Sawicki and Mariusz Szóstak analysed the post-accident protocols. Anna Hoła performed the Pareto-Lorenz analysis and ABC classification. All three authors contributed to the evaluation of the obtained results and to the text writing.

Conflicts of Interest: The authors declare no conflict of interest.

\section{References}

1. Central Statistical Office. Occupational Accidents in 2015; Department of Statistical Publishing: Warsaw, Poland, 2016.

2. Bureau of Labor Statistics (BLS). Available online: https://www.bls.gov (accessed on 11 October 2017).

3. Hoła, B.; Szóstak, M. Analysis of the State of the Accident Rate in the Construction Industry in European Union Countries. Arch. Civ. Eng. 2015, 61, 19-34. [CrossRef]

4. Hoła, B.; Sawicki, M. Tacit knowledge contained in construction enterprise documents. Procedia Eng. 2014, 85, 231-239. [CrossRef]

5. Hoła, B. Identification and evaluation of processes in a construction enterprise. Arch. Civ. Mech. Eng. 2015, 15, 419-426. [CrossRef]

6. Haslam, R.; Hide, S.; Gibb, A.; Gyi, D.; Pavitt, T.; Atkinson, S.; Duff, A. Contributing factors in construction accidents. Appl. Ergon. 2005, 36, 401-415. [CrossRef] [PubMed]

7. Hoła, B.; Szóstak, M. Analysis of the development of accident situations in the construction industry. Procedia Eng. 2014, 91, 429-434. [CrossRef]

8. Lin, Y.; Chen, C.; Wang, T. Fatal occupational falls in the Taiwan construction industry. J. Chin. Inst. Ind. Eng. 2011, 2, 586-596. [CrossRef] 
9. López Arquillos, A.; Rubio Romero, J.; Gibb, A. Analysis of construction accidents in Spain, 2003-2008. J. Saf. Res. 2012, 43, 381-388. [CrossRef] [PubMed]

10. Liy, C.; Ibrahim, S.; Affandi, R.; Rosli, N.; Nawi, M. Causes of fall hazards in construction site management. Int. Rev. Manag. Mark. 2016, 6, 257-263.

11. Whitaker, S.; Graves, R.; James, M.; McCann, P. Safety with access scaffolds: Development of a prototype decision aid based on accident analysis. J. Saf. Res. 2003, 34, 249-261. [CrossRef]

12. Suraji, A.; Duff, A.; Peckitt, S. Development of casual model of construction accident causation. J. Constr. Eng. Manag. 2001, 12, 337-344. [CrossRef]

13. Chi, S.; Han, S. Analyses of systems theory for construction accident prevention with specific reference to OSHA accident reports. Int. J. Proj. Manag. 2013, 31, 1027-1041. [CrossRef]

14. Halperin, K.; McCann, M. An evaluation of scaffold safety at construction sites. J. Saf. Res. 2004, 35, 141-150. [CrossRef] [PubMed]

15. Evanoff, B.; Dale, A.; Zeringue, A.; Fuchs, M.; Gaal, J.; Lipscomb, H.; Kaskutas, V. Results of a fall prevention educational intervention for residential construction. Saf. Sci. 2016, 89, 301-307. [CrossRef]

16. Wong, L.; Wang, Y.; Law, T.; Lo, C. Association of Root Causes in Fatal Fall-from-Height Construction Accidents in Hong Kong. J. Constr. Eng. Manag. 2016, 142, 04016018. [CrossRef]

17. Gibb, A.; Hide, S.; Haslam, R.; Hastings, S.; Suraji, A.; Duff, A.R.; Abdelhamid, T.S.; Everett, J.G. Identifying Root Causes of Construction Projects. J. Constr. Eng. Manag. 2001, 127, 348-349. [CrossRef]

18. Gibb, A.G.F.; Haslam, R.; Gyi, D.E.; Hide, S.; Duff, R. What causes accidents? Proc. ICE Civ. Eng. 2006, 159, 46-50. [CrossRef]

19. Błazik-Borowa, E.; Szer, J. The analysis of the stage of scaffolding "life" with regard to the decrease in the hazard at building works. Arch. Civ. Mech. Eng. 2015, 15, 516-524. [CrossRef]

20. Błazik-Borowa, E.; Gontarz, J. The influence of the dimension and the configuration of the geometric imperfections on the static strength of a typical façade scaffolding. Arch. Civ. Mech. Eng. 2016, 16, 269-281. [CrossRef]

21. Hoła, A.; Hoła, B.; Szóstak, M. Analysis of the causes and consequences of falls from scaffolding using the Polish construction industry as an example. IOP Conf. Ser. Mater. Sci. Eng. 2017, 251. [CrossRef]

22. Dhoka, D.; Choudary, Y. ABC Classification for Inventory Optimization. J. Bus. Manag. (IOSR-JBM) 2013, 15, 38-41. [CrossRef]

23. Chu, C.; Liang, G.; Liao, C. Controlling inventory by combining ABC analysis and fuzzy classifications. Comput. Ind. Eng. 2008, 55, 841-851. [CrossRef] 